\title{
Fuzzy logic based fault diagnosis of a PWR nuclear power plant
}

\section{Roozbeh Razavi-Far* and Hadi Davilu}

Department of Nuclear Engineering

Amirkabir University of Technology

P.O. Box 15875-4413 Tehran, Iran

E-mail: razavi_roozbeh@cic.aut.ac.ir

E-mail: davilu@aut.ac.ir

*Corresponding author

\section{Caro Lucas}

Center of Excellence on Control and Intelligent Processing Department of Electrical and Computer Engineering University of Tehran P.O. Box 14395-1515 Tehran, Iran

E-mail: lucas@ut.ac.ir

\begin{abstract}
Proper and timely fault diagnosis is of premier importance to guarantee the safe and reliable operation of Nuclear Power Plants (NPPs). If faults occur in NPPs, it is very difficult for a human operator to perform routine tasks, such as distinguishing normal from abnormal conditions and predicting future states, etc. In this paper, a fuzzy inference system is adopted for the diagnosis of abrupt faults in a nonlinear model of a typical Pressurised Water Reactor (PWR). The fuzzy system is tested with different shapes of Membership Functions (MFs). The if-then rules, representing the underlying processes, are inferred from the available fault-symptom relations. The symptoms are generated using plant model measurements.
\end{abstract}

Keywords: fault diagnosis; fault-symptom tree; fuzzy inference system; nuclear power plant; NPP.

Reference to this paper should be made as follows: Razavi-Far, R., Davilu, H. and Lucas, C. (2009) 'Fuzzy logic based fault diagnosis of a PWR nuclear power plant', Int. J. Nuclear Knowledge Management, Vol. 3, No. 3, pp.296-311.

Biographical notes: Roozbeh Razavi-Far received his BSc in Electrical Engineering, in 2001, and MSc in Nuclear Engineering in 2003 from the Amirkabir University of Technology (Tehran Polytechnic University), Iran. He is currently a $\mathrm{PhD}$ candidate at the Department of Nuclear Engineering of that university. His research interests include fuzzy systems, neural networks, genetic algorithms and their applications to intelligent control, fault detection and the isolation of nonlinear systems and fault-tolerant control systems.

Hadi Davilu received his BSc in Applied Physics from Beheshti University (Tehran), his MSc in Mechanical and Nuclear Engineering from the Sharif University of Technology (Tehran) and his $\mathrm{PhD}$ degree in Mechanical 
Engineering from Ruhr University of Bochum, Germany. He is an Associate Professor at the Department of Nuclear Engineering of the Amirkabir University of Technology (Tehran Polytechnic University), Iran. His research interests include the safety and reliability of nuclear systems, natural circulation and thermal hydraulic analysis.

Caro Lucas received his MSc in Electrical Engineering from the University of Tehran, Iran, in 1973 and his PhD from the University of California, Berkeley, in 1976. He is a Professor and a member of the Center of Excellence for Control and Intelligent Processing, Department of Electrical and Computer Engineering, University of Tehran. His research interests include biological computing, computational intelligence, uncertain systems, intelligent control, neural networks and multi-agent systems. He has served as an Associate Editor of the Journal of Intelligent and Fuzzy Systems (1992-1999) and Chairman of the IEEE, Iran Section (1990-1992).

\section{Introduction}

Large-scale systems such as Nuclear Power Plants (NPPs) are increasingly relied upon to provide safe, reliable operations for long periods of time. Unfortunately, all of these systems' components are subject to manufacturing defects, interactions with the environment, wear and tear and other causes of performance degradations. For these safety-critical systems, the problem of detecting faults' occurrence is of high importance due to their disastrous consequences. Contemporary diagnostics of processes is mainly based on process models and to detect the occurrence of a fault, a model of the normal process behaviour is needed. The current process behaviour is compared with the normal process behaviour. The comparison of the observed features with the nominal behaviour of the process leads to residuals. The detectable deflections of the residuals yield to symptoms. The symptoms are then processed in the subsequent fault diagnosis by means of fault-symptom-causality. The faults are located and the fault causes are determined (Frank, 1990). For the latter stage of fault diagnosis, classification or inference methods (including fault-symptom trees, fuzzy rules or neural approaches) can be used (Isermann, 2005). If no information is available on the fault-symptom casualties, trained classification methods can be applied for fault diagnosis. This leads to an unstructured knowledge base. The classification approaches to fault diagnosis have been presented in many works. Previous methods to identify NPP transients were based on the time-series data of various transient signals. Various diagnostic methods were worked out. The following approaches were applied: neural networks approaches (Bartal et al., 1995; Embrechts and Benedek, 2004) and pattern classification by fuzzy clustering approaches (Marseguerra et al., 2003; Zio and Baraldi, 2005). However, such techniques need a large amount of fault data to extract the features of individual faults or expert knowledge about the system and its misbehaviour.

If the fault-symptom causalities can be expressed in the form of 'if-then' rules, reasoning or inference methods are applicable. In this case, one of the powerful tools for fault diagnosis is fuzzy logic. Indeed, the key benefit of fuzzy logic is that it lets the operator describe the system behaviour or fault-symptom relationship with simple 
if-then rules. The diagnostic system developed in this work uses the Mamdani inference strategy due to transparent reasoning that allows the user to understand the inference of the system and support the operator in decision making.

The proposed diagnostic method is validated with a Pressurised Water Reactor (PWR). In this work, we focus on the area of abrupt faults similar to most of the transients occurring at NPPs. Abrupt faults are injected into a nonlinear PWR simulator developed by MATLAB SIMULINK. The PWR simulator was built based on a nonlinear model of a typical PWR power plant (Naghedolfeizi and Upadhyaya, 1992). The fuzzy diagnostic module connected to the simulation and the Mamdani approach is used for generating fault diagnosis rules based on the knowledge of the operator about the fault-symptom relations. The proposed faults are Main Steam Line Break (MSLB), Loss of Coolant Accident (LOCA), fault in the Pressuriser Heater Control (PHC), fault in the Pressuriser Spray Control (PSC) and blockage in Feedwater Piping (BFWP).

The paper is organised as follows. Section 2 introduces the fuzzy diagnostic module from the topological point of view. In this section, the theoretical aspects of the employed fuzzy inference methodology for Fault Detection and Isolation (FDI) are presented. Section 3 describes the typical abrupt faults in the PWR NPP and shows how the faults can be injected into the PWR simulation. In this section, the fault-symptom trees are used to analyse and identify the source of the faults by evaluating the combination of basic events (fault symptoms) which can lead to a root event (a particular fault). Section 4 presents an application of the fuzzy inference system to the fault diagnosis of the case study and the obtained results. Finally, the conclusions are drawn in Section 5.

\section{The fuzzy diagnostic module}

Fuzzy logic systems are widely proposed in modern diagnostic technologies. The relationships between residuals and the faulty states of the monitored system are expressed by a set of if-then rules. The structure of a typical fuzzy diagnosis system is composed of a set of if-then rules. If multiple fault situations are to be distinguished, one will have a structure as seen in Figure 1. The inputs are the symptoms $S_{\mathrm{i}}$. The aim of the fuzzy diagnosis is to implement linguistic rules $R$ of the kind

$$
R: \text { If }\left\langle\ell\left\{(\ldots),\left(\mathrm{S}_{\mathrm{i}} \text { is } A_{11}\right), \ldots,(\ldots)\right\}\right\rangle \quad \text { Then }\left\langle\mathrm{f}_{\mathrm{j}} \text { is } A_{\mathrm{F} 1}\right\rangle
$$

to draw conclusions from the symptoms $S_{i}$ to the fault measures $f_{j}$.

The premise of the rule is comprised in general multiple linguistic statements that are combined by operators $\ell$. An example is the statement 'symptom $\mathrm{S}_{1}$ ' and the linguistic value 'increased'. The first step towards rule evaluation is the computation of the membership values $\mu_{\mathrm{A}}\left(\mathrm{S}_{\mathrm{i}}\right)$ to the linguistic value $A$. This is called fuzzification and consists of the evaluation of the individual Membership Functions (MFs) such as the one in Equation (1). The next step is inference. This term denotes the evaluation of the linguistic rules and the combination of the action list of the rule basis with a linguistic conclusion. The inference consists of the premise evaluation, the activation and the accumulation. The premise evaluation combines the membership degree of the individual rule premise terms. The task is to utilise the linguistic operators $\ell$ of the rule to combine the linguistic values. The activation is now the application of the rule fulfillments to the rule consequences. The accumulation combines the activated output MFs for every 
linguistic output variable. The result of the accumulation is then a linguistic output variable as a fuzzy set. The fuzzy set is transferred into a crisp output value by defuzzification.

Figure 1 The fuzzy logic system for fault diagnosis

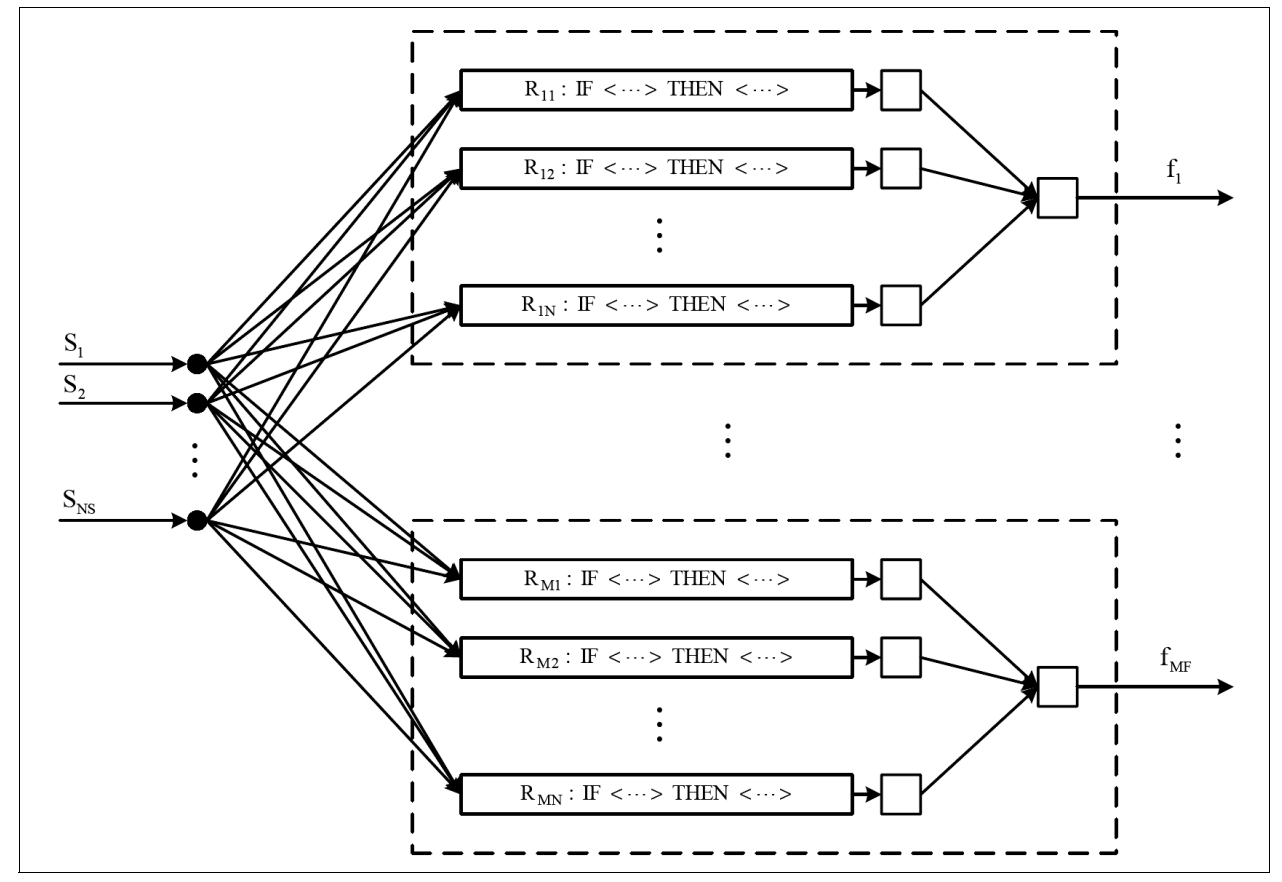

There are two main types of fuzzy inference methods known in the literature: Mamdani and Takagi-Sugeno. Generally, Takagi-Sugeno structures are frequently used if knowledge can be extracted from raw data and Mamdani systems are preferred when knowledge is given by human experts in the form of linguistic expressions. The diagnostic system developed in this work uses the Mamdani inference strategy due to transparent reasoning that allows the user to understand the inference of the system and support the operator in decision making during normal and faulty conditions.

\section{Fault simulation and fault-symptom tree analysis}

An NPP is a complex system which has more than one variable influencing its dynamic behaviour. Deviation in any variable due to normal or abnormal events will almost simultaneously initiate a change in most of the other variables. This occurs due to the strong and fast coupling among system process variables, especially in the nuclear system. To follow the dynamic change of the plant for continuous control and safe operation, definition and identification have to be made for those variables which directly affect plant safety. These variables will then continuously be monitored and controlled during different phases of plant operation. A detailed nonlinear model for a typical PWR 
system has been considered for the development of a PWR simulator. Each component in the PWR system has been represented by appropriate nonlinear differential equations which are solved simultaneously. Then, the overall PWR NPP model is constructed by connecting individual components to each other. The validity of models for the individual components and overall system has been verified. The simulation results are compared with reported results from similar studies (Naghedolfeizi and Upadhyaya, 1992). Abrupt faults are applied to the simulation via step changes in some variables. The simulation is run for $100 \mathrm{sec}$. The locations of the critical plant parameters and symptoms used for this study are shown in Figure 2.

Figure 2 The schematic of a PWR power plant with critical plant parameter

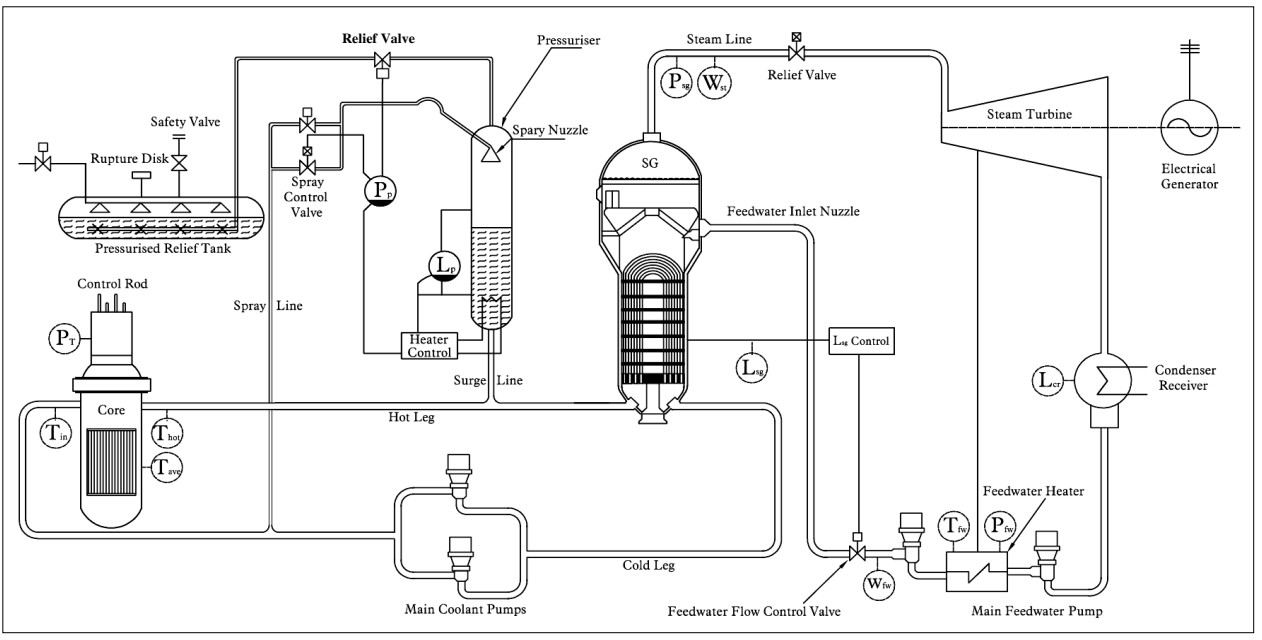

Fault-symptom trees are used to evaluate the behaviour of the plant in faulty conditions. In the fault-symptom tree, faults are typically located at the top of the tree, while other events form the branches and leaves of the tree. The events in nodes are described by qualitative variables and are connected by AND/OR logical relations. If faults occur in the plant, fault-symptom trees can be used to identify the cause of the faults by evaluating the combinations of basic events (fault symptoms) which can lead to a root event or a particular fault. Therefore, heuristic knowledge of the process in the form of fault-symptom causalities is evaluated by forward chaining the observed symptoms to establish possible causes. These fault-symptom relationships are used to generate the rule base of the fuzzy diagnostic module.

\subsection{Main Steam Line Break (MSLB)}

The MSLB is a break in the main steam line that connects the steam generator to the steam turbine and feedwater heater. To simulate the fault, the value of the steam generator flow is reduced from a normal value to zero. The steam turbine input then remains constant $(0 \mathrm{~kg} / \mathrm{s})$. After a set point, the steam generator flow is switched from its normal operational value to a reduced value through a SW triggered by a simple step input. The trigger time is $5 \mathrm{sec}$, which is typical. At this time, the steam generator flow is 
changed from its normal value to the faulty value $(0 \mathrm{~kg} / \mathrm{s})$. Once the fault is injected into the simulation, the total reactor power $\left(\mathrm{P}_{\mathrm{T}}\right)$, hot leg temperature $\left(\mathrm{T}_{\mathrm{hot}}\right)$ and cold leg temperature $\left(\mathrm{T}_{\mathrm{in}}\right)$ are decreased. The resulting symptoms of the fault are as follows:

- $\mathrm{S}_{1}-$ Decrease in core coolant average temperature $\left(\mathrm{T}_{\mathrm{ave}}\right)$

- $\mathrm{S}_{2}-$ Decrease in pressuriser pressure $\left(\mathrm{P}_{\mathrm{p}}\right)$

- $\mathrm{S}_{3}$ - Increase in pressuriser water level $\left(\mathrm{L}_{\mathrm{p}}\right)$

- $\mathrm{S}_{4}-$ Decrease in steam generator pressure $\left(\mathrm{P}_{\mathrm{sg}}\right)$

- $\mathrm{S}_{5}-$ Decrease in steam generator steam flow $\left(\mathrm{W}_{\mathrm{stm}}\right)$

- $\mathrm{S}_{6}-$ Decrease in steam generator water level $\left(\mathrm{L}_{\mathrm{sg}}\right)$

- $\mathrm{S}_{7}$ - Decrease in condensate receiver water level $\left(\mathrm{L}_{\mathrm{cr}}\right)$

- $\mathrm{S}_{8}-$ Decrease in feedwater pressure $\left(\mathrm{P}_{\mathrm{fw}}\right)$

- $\mathrm{S}_{9}-$ Decrease in feedwater flow $\left(\mathrm{W}_{\mathrm{fw}}\right)$

- $\mathrm{S}_{10}$ - Decrease in feedwater temperature $\left(\mathrm{T}_{\mathrm{fw}}\right)$.

Figure 3 illustrates the fault-symptom tree for $\operatorname{MSLB}\left(\mathrm{f}_{4}\right)$, which can be constructed from analysing the symptoms. The MSLB is a consequence of the event node, which is a combination of $\mathrm{S}_{3}, \mathrm{~S}_{6}, \mathrm{~S}_{7}, \mathrm{~S}_{8}$ and $\mathrm{S}_{10}$ (AND). Each of these symptoms has three states: decrease, constant and increase. In Figure 3, the $[+,-]$ markings next to the arrows linking the symptoms indicate that the connected symptoms change in the same $[+]$ or opposite [-] direction.

Figure 3 The fault-symptom tree for an MSLB

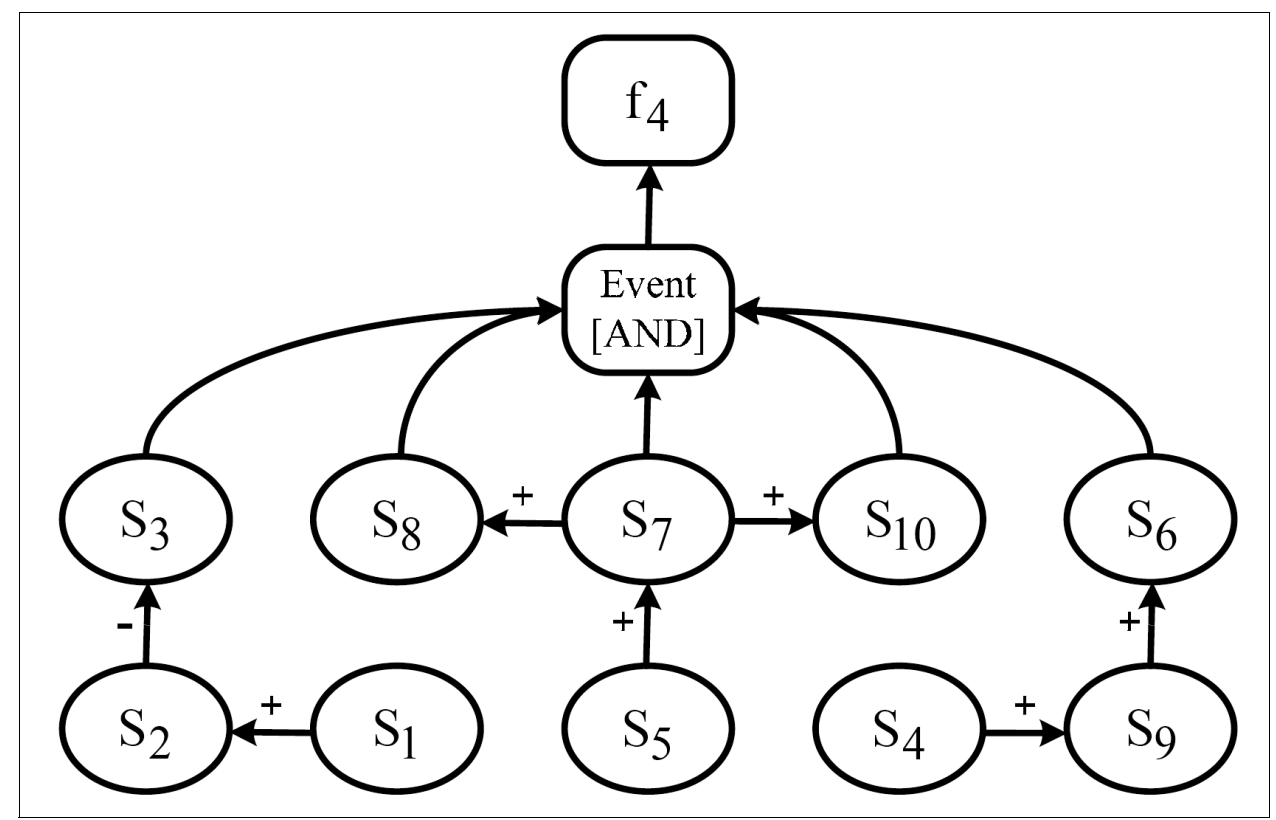


The fault-symptom tree for MSLB shows that a decrease in the steam generator water level $\left(\mathrm{S}_{6}\right)$ is a consequence of a decrease in the feedwater flow $\left(\mathrm{S}_{9}\right)$ and that $\mathrm{S}_{9}$ is a consequence of a decrease in the steam generator pressure $\left(\mathrm{S}_{4}\right)$. An increase in the pressuriser water level $\left(\mathrm{S}_{3}\right)$ is a consequence of the decrease in pressuriser pressure $\left(\mathrm{S}_{2}\right)$ and $S_{2}$ is a consequence of a decrease in the core coolant's average temperature (S1). A decrease in the condensate receiver water level $\left(\mathrm{S}_{7}\right)$ is a consequence of a decrease in the steam generator steam flow $\left(\mathrm{S}_{5}\right)$. A decrease in the feedwater pressure $\left(\mathrm{S}_{8}\right)$ and the feedwater temperature $\left(S_{10}\right)$ is the consequence of a decrease in the condensate receiver water level $\left(\mathrm{S}_{7}\right)$.

\subsection{Loss of Coolant Accident (LOCA)}

To simulate this fault, a fault block is placed at the reactor hot leg. After a set time, the primary coolant flow in the hot leg is switched from its normal operational value to a reduced value through an SW triggered by a simple step input. The trigger time is $10 \mathrm{sec}$, which is typical. The primary coolant flow is changed from its normal value to a leakage value ( $70 \%$ of the normal primary coolant flow). The resulting symptoms of the fault are listed in Table 1.

Table 1 The fuzzy rule base table for a PWR plant

\begin{tabular}{llcccccc}
\hline \multicolumn{2}{l}{ Symptoms } & $f_{1}($ LOCA $)$ & $f_{2}($ PHC) & $f_{3}($ PSC $)$ & $f_{4}($ MSLB $)$ & $f_{5}($ BFWP $)$ & No fault \\
\hline $\mathrm{S}_{1}$ & $\mathrm{~T}_{\mathrm{ave}}$ & $\downarrow$ & $\leftrightarrow$ & $\leftrightarrow$ & $\downarrow$ & $\leftrightarrow$ & $\leftrightarrow$ \\
$\mathrm{S}_{2}$ & $\mathrm{P}_{\mathrm{p}}$ & $\downarrow$ & $\uparrow$ & $\leftrightarrow$ & $\downarrow$ & $\leftrightarrow$ & $\leftrightarrow$ \\
$\mathrm{S}_{3}$ & $\mathrm{~L}_{\mathrm{p}}$ & $\downarrow$ & $\uparrow$ & $\uparrow$ & $\uparrow$ & $\leftrightarrow$ & $\leftrightarrow$ \\
$\mathrm{S}_{4}$ & $\mathrm{P}_{\mathrm{sg}}$ & $\uparrow$ & $\leftrightarrow$ & $\leftrightarrow$ & $\downarrow$ & $\leftrightarrow$ & $\leftrightarrow$ \\
$\mathrm{S}_{5}$ & $\mathrm{~W}_{\mathrm{stm}}$ & $\downarrow$ & $\leftrightarrow$ & $\leftrightarrow$ & $\downarrow$ & $\leftrightarrow$ & $\leftrightarrow$ \\
$\mathrm{S}_{6}$ & $\mathrm{~L}_{\mathrm{sg}}$ & $\downarrow$ & $\leftrightarrow$ & $\leftrightarrow$ & $\downarrow$ & $\downarrow$ & $\leftrightarrow$ \\
$\mathrm{S}_{7}$ & $\mathrm{~L}_{\mathrm{cr}}$ & $\uparrow$ & $\leftrightarrow$ & $\leftrightarrow$ & $\downarrow$ & $\uparrow$ & $\leftrightarrow$ \\
$\mathrm{S}_{8}$ & $\mathrm{P}_{\mathrm{fw}}$ & $\uparrow$ & $\leftrightarrow$ & $\leftrightarrow$ & $\downarrow$ & $\uparrow$ & $\leftrightarrow$ \\
$\mathrm{S}_{9}$ & $\mathrm{~W}_{\mathrm{fw}}$ & $\downarrow$ & $\leftrightarrow$ & $\leftrightarrow$ & $\downarrow$ & $\downarrow$ & $\leftrightarrow$ \\
$\mathrm{S}_{10}$ & $\mathrm{~T}_{\mathrm{fw}}$ & $\uparrow$ & $\leftrightarrow$ & $\leftrightarrow$ & $\downarrow$ & $\uparrow$ & $\leftrightarrow$ \\
\hline
\end{tabular}

Notes: $\quad(\downarrow)$ is decrease, $(\uparrow)$ is increase, and $(\leftrightarrow)$ is constant.

\subsection{Fault in the Pressuriser Heater Control (PHC)}

To simulate this fault using the PHC system, the cycling heater set point was changed from $1545 \mathrm{kPa}$ to $1550 \mathrm{kPa}$ and, similarly, the backup heater set point was changed from $1540 \mathrm{kPa}$ to $1545 \mathrm{kPa}$, with the threshold of the SW control set to $1550 \mathrm{kPa}$. If the pressuriser pressure is equal to this value, the cycling heater SW will be turned off. In turn, the backup heater SW is switched when the pressuriser pressure is $1545 \mathrm{kPa}$. The resulting symptoms of the fault are the increase in pressuriser pressure $\left(\mathrm{S}_{2}\right)$ and the increase in the pressuriser water level $\left(\mathrm{S}_{3}\right)$, as reported in Table 1 . 


\subsection{Fault in the Pressuriser Spray Control (PSC)}

To simulate a fault in the PSC during the normal operation of the reactor, the pressuriser spray flow is set to the ON position when the pressuriser pressure is $1550 \mathrm{kPa}$. When the set point value is changed from $1550 \mathrm{kPa}$ to $1545 \mathrm{kPa}$, the pressuriser water spray rate is decreased. To generate this fault by using an SW, its threshold is changed from $1550 \mathrm{kPa}$ to $1545 \mathrm{kPa}$. That is, when the pressuriser pressure equals this value, the pressuriser spray rate SW is switched from OFF to ON. The PSC has just one symptom (see Table 1), which is the increase in pressuriser water level $\left(\mathrm{S}_{3}\right)$.

\subsection{Blockage in Feedwater Piping (BFWP)}

To simulate this fault, a fault block is placed between the junction of the feedwater, steam turbine and steam generator. After a set time, the feedwater flow is switched from its normal operational value to a reduced value via an SW triggered by a simple step input. The trigger time is $10 \mathrm{sec}$, which is typical. The feedwater flow is changed from its normal value to a blockage value ( $70 \%$ of the normal flow). The resulting symptoms of the fault are listed in Table 1.

\section{Fuzzy inference approach applied to the fault diagnosis of the PWR power plant}

Abrupt faults are injected into the proposed PWR simulator via switches. The fuzzy diagnostic module connected to the Simulink simulation and the Mamdani approach is used for generating fault diagnosis rules based on a priori knowledge about fault-symptom relations, which can be inferred from fault-symptom trees. The details of the connection between the PWR simulation and fuzzy diagnostic system are shown in Figure 4. The symptom scaling block is built using Simulink and the fuzzy inference system is implemented using the Matlab FL toolbox. The inputs of the symptom scaling block $\left(\mathrm{S}_{1}, \mathrm{~S}_{2}\right.$, etc. $)$ are the outputs of the simulation model, namely the variables of the PWR NPP (ten symptoms). The simulator provides two outputs for each variable: the value under Faulty Condition (FV) and a Normal Value (NV) from the reference model. These values are stored as a separate vector of the normal and faulty values for each sampling interval (typically 1000 from a 100 -sec simulation time).

The inputs to the scaling section go to a demultiplexer (Demux) which separates the vector line into two values ( $\mathrm{NV}$ and FV). The next stage is a sum block, which gives the difference between the normal value and the faulty value. This value (residual) will be scaled to accommodate the fuzzy logic toolbox inputs, e.g., if the difference of the first variable ranges between $[-1,1]$ and the fuzzy logic toolbox range is $[-3,3]$, then the input variable has to be scaled to the fuzzy logic toolbox input range. Therefore, a gain block (FL toolbox input range/range of symptoms) has been used to scale the input. Before feeding the scaled input to the fuzzy logic toolbox, it is fed through the saturation block to keep the input within a specified range $[-3,3]$. The ranges used for each variable are given in Table 2. In normal operational conditions, the variables have steady-state values, as shown in Table 2. Any change in the variable values generates the symptoms. For each symptom, one limit value has been designed to indicate a decrease or increase 
from the normal operation limit, as shown in Table 2. These limits are the upper bounds of the membership functions. The Universe of Discourse (UOD) value determines the value of the MF by using the following equation:

$$
\frac{6 \times(\mathrm{NV}-\mathrm{FV})}{\mathrm{RS}}=\text { Value of UOD, }
$$

where:

$$
\begin{aligned}
& \mathrm{NV}=\text { the normal variable's value } \\
& \mathrm{FV}=\text { the faulty variable's value } \\
& \mathrm{RS}=\text { the range of symptoms for each variable. }
\end{aligned}
$$

For each input variable, an MF is defined corresponding to a decrease, constant and increase state, as shown in Figure 5. Tests can be run with different shapes of the functions. The output MFs for the faults are defined in Figure 6.

Figure 4 Diagram of a fault diagnostic system

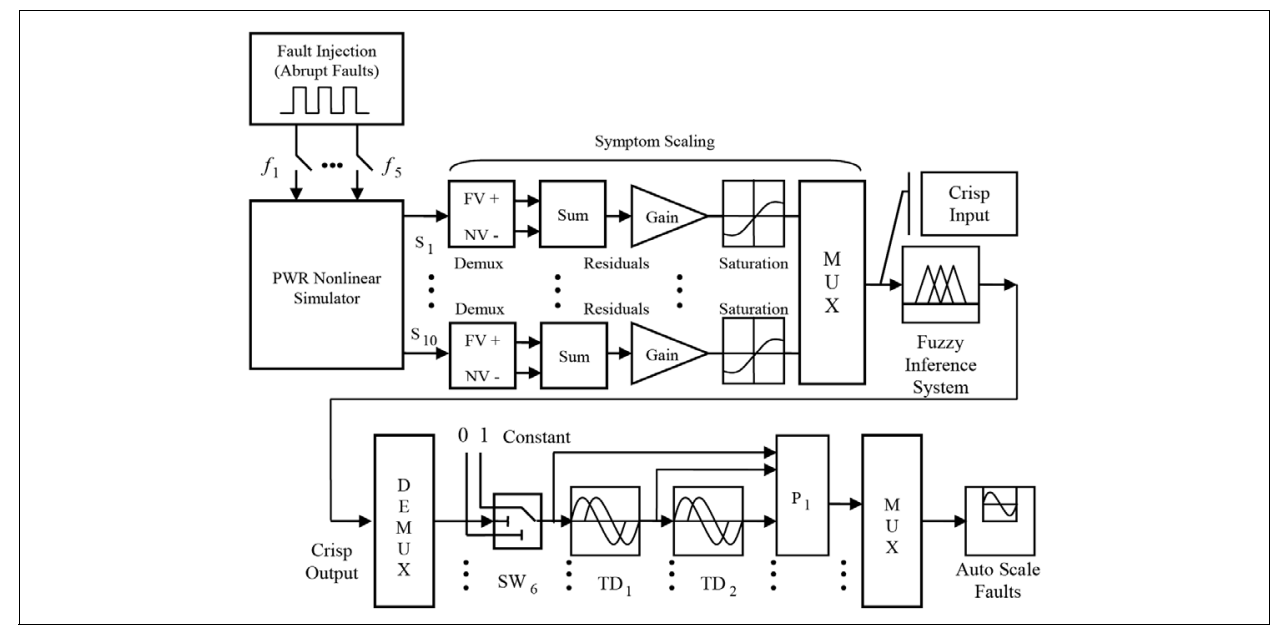

Table 2 The steady-state values and limit values for variables in the PWR model

\begin{tabular}{lcc}
\hline Symptom variables & Steady-state values & Limit values \\
\hline Core coolant average temperature $\left(\mathrm{T}_{\mathrm{ave}}\right)$ & $289^{\circ} \mathrm{C}$ & $\pm 1^{\circ} \mathrm{C}$ \\
Pressuriser pressure $\left(\mathrm{P}_{\mathrm{p}}\right)$ & $15.5 \mathrm{MPa}$ & $\pm 69 \mathrm{kPa}$ \\
Pressuriser water level $\left(\mathrm{L}_{\mathrm{p}}\right)$ & $1188 \mathrm{~mm}$ & $\pm 38 \mathrm{~mm}$ \\
Steam generator pressure $\left(\mathrm{P}_{\mathrm{sg}}\right)$ & $5.2 \mathrm{MPa}$ & $\pm 15.5 \mathrm{kPa}$ \\
Steam generator steam flow $\left(\mathrm{W}_{\mathrm{stm}}\right)$ & $26.15 \mathrm{~kg} / \mathrm{s}$ & $\pm 4.5 \mathrm{~kg} / \mathrm{s}$ \\
Steam generator water level $\left(\mathrm{L}_{\mathrm{sg}}\right)$ & $3200 \mathrm{~mm}$ & $\pm 255 \mathrm{~mm}$ \\
Condensate receiver water level $\left(\mathrm{L}_{\mathrm{cr}}\right)$ & $2337 \mathrm{~mm}$ & $\pm 76 \mathrm{~mm}$ \\
Feedwater pressure $\left(\mathrm{P}_{\mathrm{fw}}\right)$ & $8.7 \mathrm{MPa}$ & $\pm 20.68 \mathrm{kPa}$ \\
Feedwater flow $\left(\mathrm{W}_{\mathrm{fw}}\right)$ & $25.85 \mathrm{~kg} / \mathrm{s}$ & $\pm 4.5 \mathrm{~kg} / \mathrm{s}$ \\
Feedwater temperature $\left(\mathrm{T}_{\mathrm{fw}}\right)$ & $212^{\circ} \mathrm{C}$ & $\pm 0.55^{\circ} \mathrm{C}$ \\
\hline
\end{tabular}


Figure 5 The MF for inputs (symptoms)

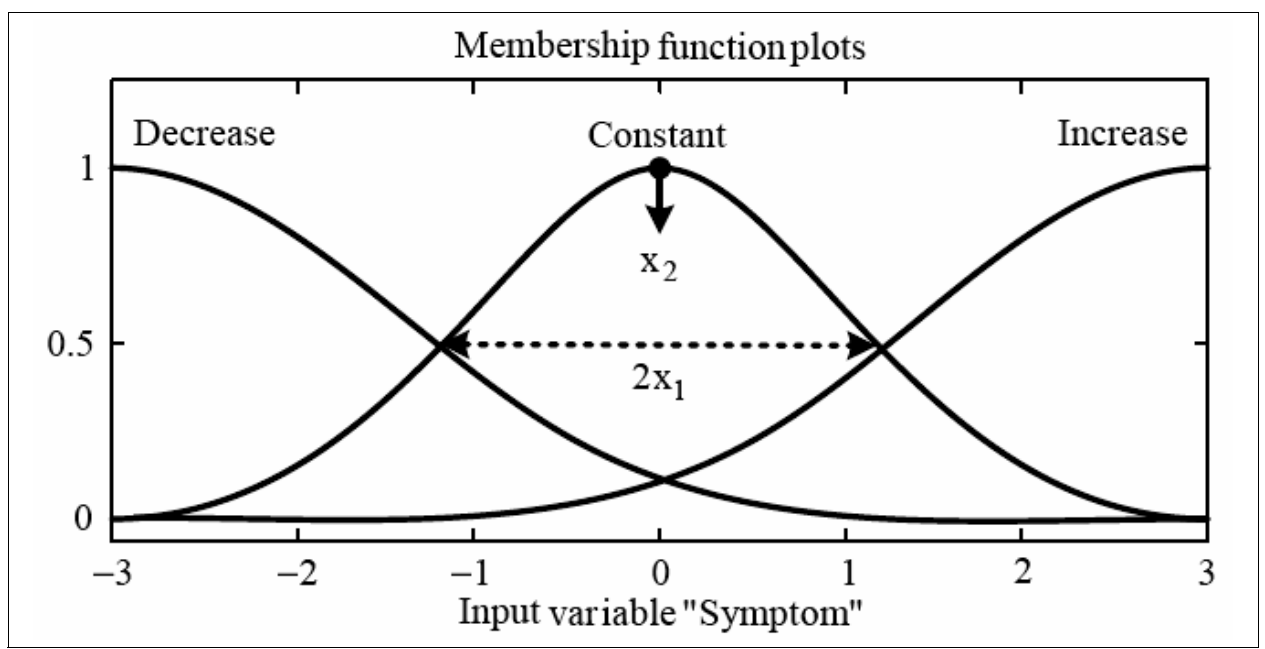

Figure 6 The MF for outputs (faults)

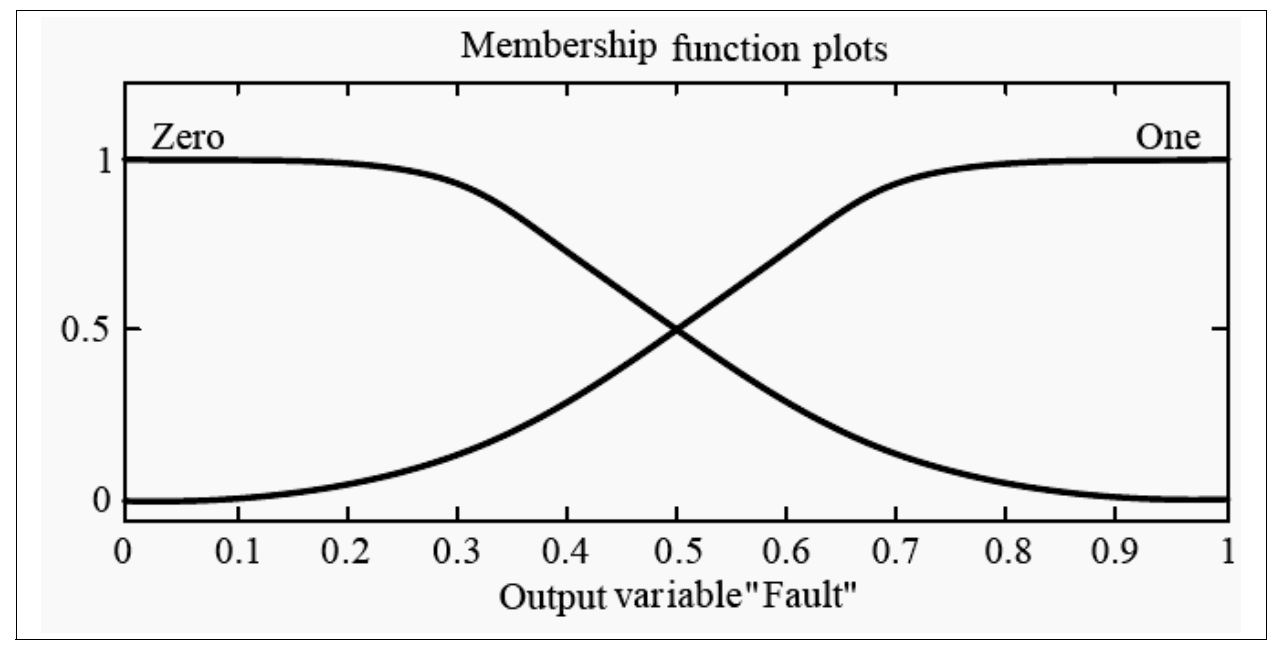

The saturation block imposes upper and lower bounds on a signal within the range of the specified limits. Therefore, the input signal will pass through unchanged if it is within the bounds. Outside these bounds, a signal is clipped to the maximum or minimum bound. This is the MF range, which is $[-3,3]$. The input values of the fuzzy logic toolbox are inside the limit range and those values determine if the variable's value has to be changed or not. Also, the range for the output membership functions $[0,1]$ is shown in Figure 6 and MFs have two situations (zero (no fault), one (fault)). To determine an active fault in the PWR model, the outputs of the fuzzy logic toolbox are applied to an SW block which supports multivariate input and output. The SW block has three inputs and one output. If the signal on the second input is greater than or equal to the threshold (0.5), then the first input is propagated, which is one (fault); otherwise, the third input drives the output, which is zero (no fault). A delay mechanism has been used to ensure that only persistent 
faults are detected. If the fault occurs in only one sample, it will be eliminated through this mechanism. For a certain fault, if the fault lasts for more than $6 \mathrm{sec}$, it will be propagated through the Transport Delay (TD) blocks, where the product of all three delayed values is an active fault. The final decision will be a true fault. This mechanism will have an effect on reporting the fault instantly when it occurs. As the delay will check for a persistent fault for $6 \mathrm{sec}$, it will only report an active fault after $12 \mathrm{sec}$. Finally, auto scale faults generate a fault graph during simulation time.

The rule base of the fuzzy inference system can be constructed using fault-symptom relations, as shown in Table 1. Each symptom has three positions (decrease, constant and increase), which can be used as input MFs for each fault. The input MFs are referenced by the antecedent or if-part (symptoms) of each rule. The output MFs are referenced by the consequent or then-part (faults). The crisp inputs are the scaled symptoms that feed into the fuzzy diagnostic module. The fuzzification module converts the crisp variables coming from the plant into fuzzy sets, as defined by their MFs. The fuzzy rule base is founded on a set of if-then rules, the so-called knowledge base. The generic fuzzy rule is made up of a number of antecedent and consequent linguistic statements which are suitably related by fuzzy connections (Equation 1). For example, the rule for BFWP has the following form: If $\left\langle\left\{(\ldots), \ldots,\left(\mathrm{S}_{6}\right.\right.\right.$ is Decrease),..., (...) $\left.\}\right\rangle$, as shown in the seventh column of Table 1 , then $\left\langle\mathrm{f}_{5}\right.$ is an active fault $\rangle$.

The fuzzy inference engine receives at anytime the linguistic variables that are sent by the fuzzification module, which constitute the fact. The fuzzy engine compares these data with those in the antecedents of the fuzzy rule base and arrives at the conclusion (a particular fault or a normal operation). Finally, aggregation occurs and a crisp output is generated in the defuzzification module. If the aggregated value is over 0.5 , this means that the proposed fault (i.e., BFWP) is active. Other faults can be similarly explained.

\subsection{Test results}

The fuzzy fault diagnosis system is tested with different shapes of MFs to find the efficient MF for the fault diagnosis of PWR. In this work, the change in shape of the MF gives different results during simulation for the same fault, as indicated in Table 3. The different shapes of the MF, such as bell-shaped, triangular, two-sided composite Gaussian, simple Gaussian and mixed Gaussian (simple and two-sided) curves, are used as input MFs. The relationship between the results and the shape of the MF is shown in Figure 7, 8, 9, 10 and 11. Table 3 presents the different shapes of input MFs and their parameters. From the test results, it is found that the simple and two-sided Gaussian MF is more efficient for fault diagnosis. For example, to diagnose the BFWP fault by using the fuzzy inference approach, simple Gaussian curves are used as membership functions, with following parameters [1.3 -3], [1.3 0], [1.3 3], (see Table 3). The results are shown in Figure 10. In this case all faults are close to critical position and behavior of fuzzy model. For that reason, mixed shapes of input MFs are used, such as simple and two-sided composite Gaussian curves (Figure 11). In this case the simple Gaussian curve is used for decrease and increase MFs and the two-sided composite Gaussian curve is used for constant MF. The Gaussian curve parameters of decrease and increase MFs have been changed from [1.3 -3], [1.3 3] to [1.8 -3], [1.8 3], where parameters [X1 X2] are shown in Figure 5. The results appear to be reasonable. 
Table 3 The relationship between the shape of the MF and FDI

\begin{tabular}{|c|c|c|}
\hline Shape of $M F$ & MF parameters & Fault indication \\
\hline Bell-shaped & $\begin{array}{l}{\left[\begin{array}{lll}2.2 & 3.278 & -3\end{array}\right]} \\
{\left[\begin{array}{lll}1.53 & 3.28 & 0\end{array}\right]} \\
{\left[\begin{array}{lll}2.2 & 3.278 & 3\end{array}\right]}\end{array}$ & $\begin{array}{l}\text { Critical position } \\
\text { Does not detect any fault }\end{array}$ \\
\hline Triangular & 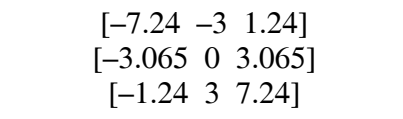 & $\begin{array}{l}\text { Critical position } \\
\text { Unsuitable for FDI }\end{array}$ \\
\hline Two-sided Gaussian & $\begin{array}{c}{\left[\begin{array}{cccc}1.098 & -3.825 & 1.098 & -2.175\end{array}\right]} \\
{\left[\begin{array}{llll}0.79 & -0.596 & 0.79 & 0.596\end{array}\right]} \\
{\left[\begin{array}{llll}1.098 & 2.175 & 1.098 & 3.825\end{array}\right]}\end{array}$ & $\begin{array}{l}\text { Critical position } \\
\text { Unsuitable for FDI }\end{array}$ \\
\hline Simple Gaussian & $\begin{array}{l}{\left[\begin{array}{cc}1.3 & -3\end{array}\right]} \\
{\left[\begin{array}{ll}1.3 & 0\end{array}\right]} \\
{\left[\begin{array}{ll}1.3 & 3\end{array}\right]}\end{array}$ & $\begin{array}{l}\text { Critical position } \\
\text { Unsuitable for FDI }\end{array}$ \\
\hline $\begin{array}{l}\text { Simple and two-sided } \\
\text { Gaussian }\end{array}$ & 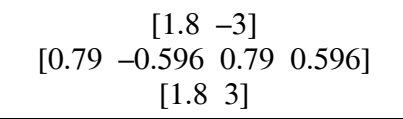 & $\begin{array}{l}\text { Reasonable } \\
\text { Suitable for FDI }\end{array}$ \\
\hline
\end{tabular}

Figure 7 The faults in the PWR model using the bell-shaped MF

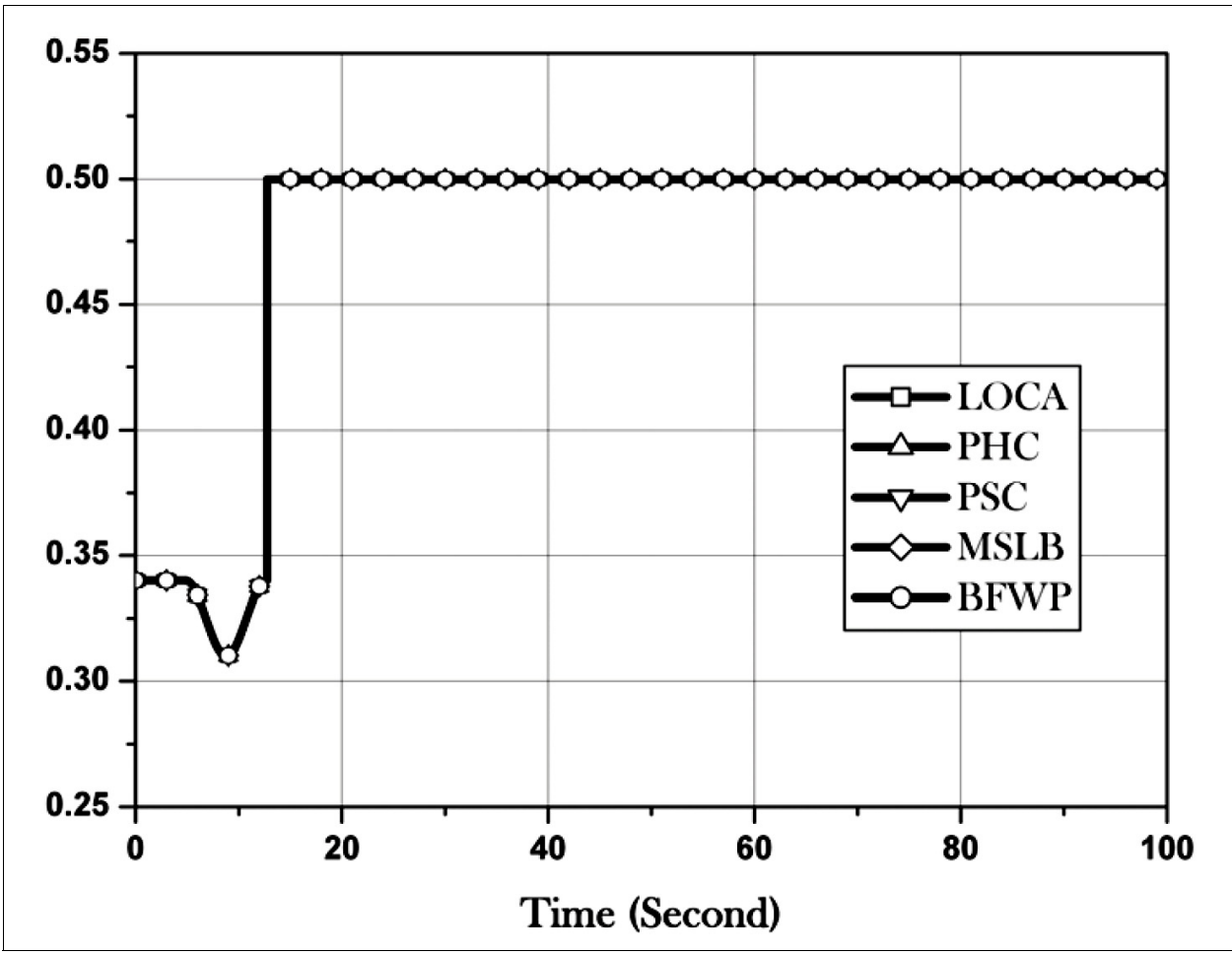


Figure 8 The faults in the PWR model using the triangular MF

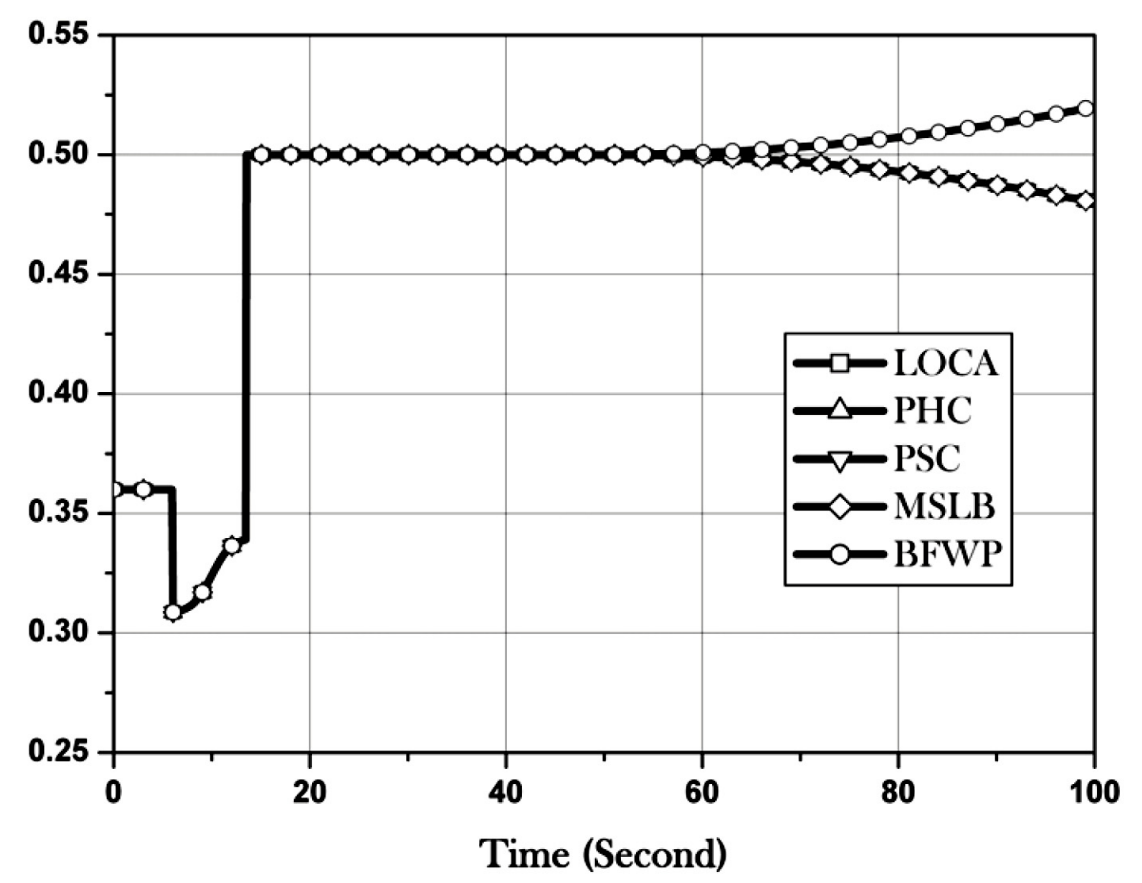

Figure 9 The faults in the PWR model using the two-sided Gaussian MF

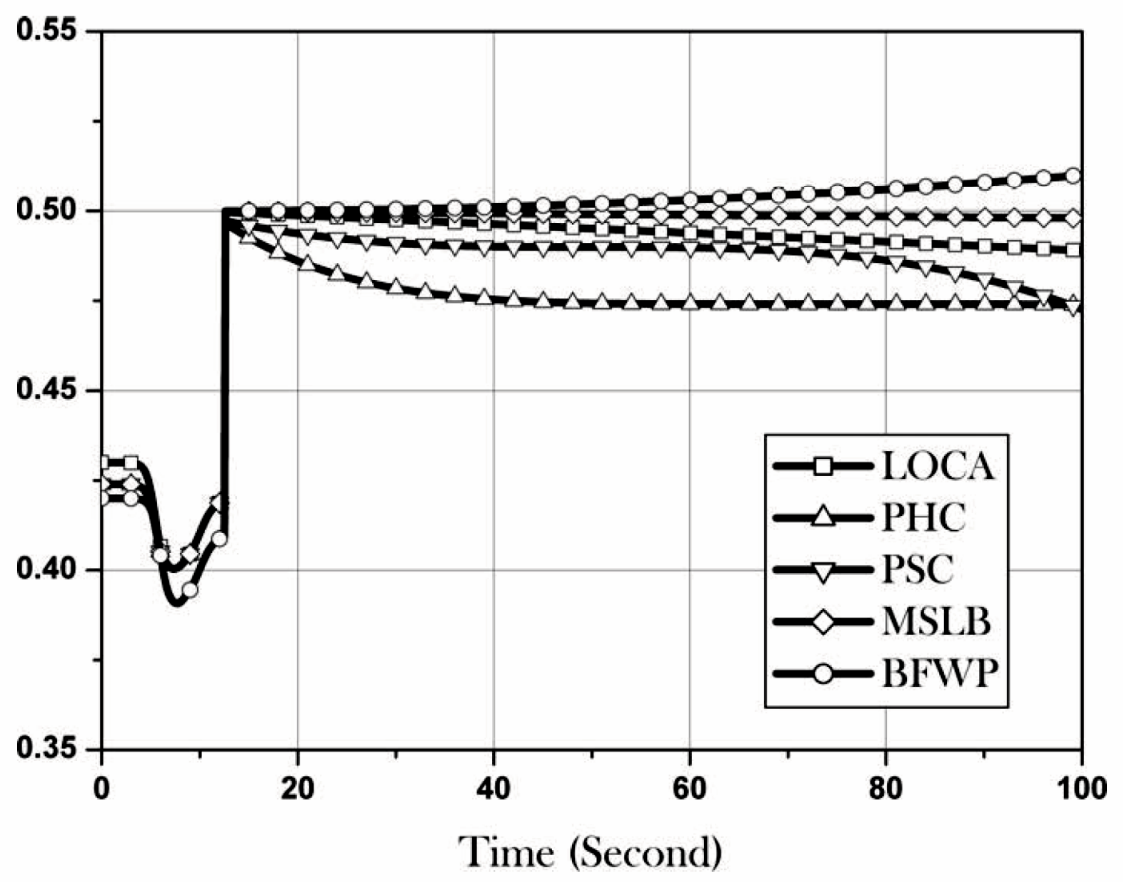


Figure 10 The faults in the PWR model using the simple Gaussian MF

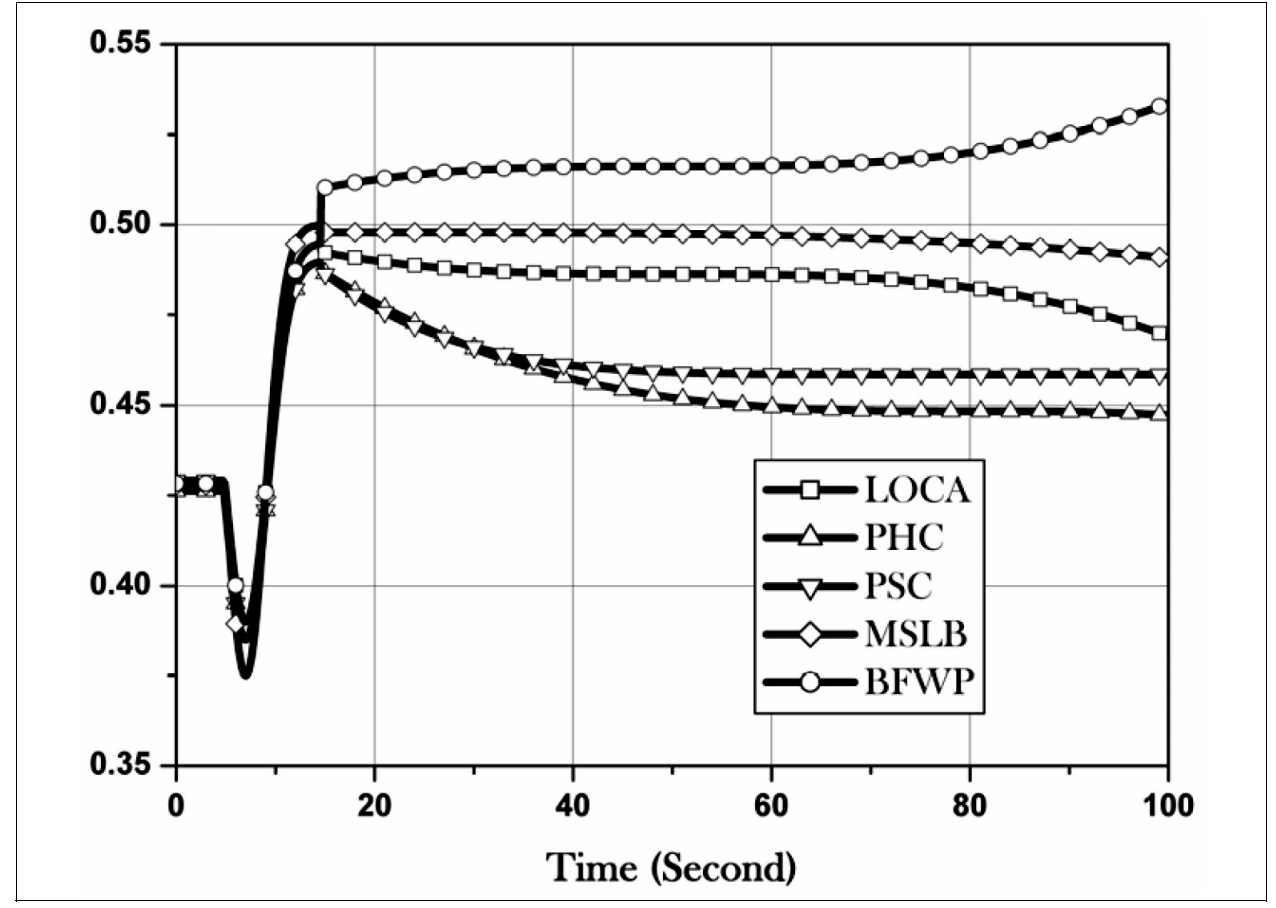

Figure 11 The faults in the PWR model using the mixed Gaussian MF

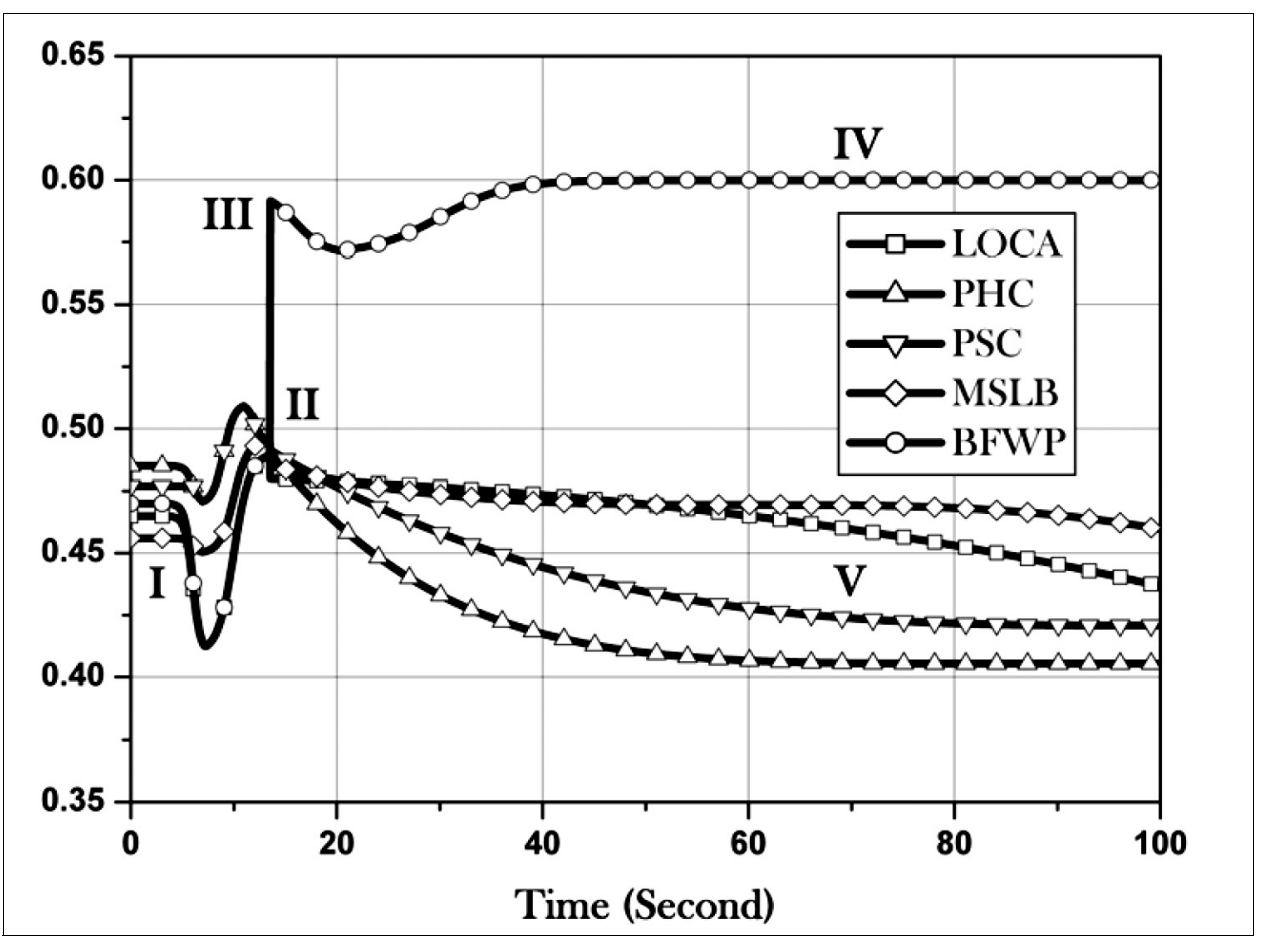


Figure 11 illustrates the change of faults during simulation time for BFWP. After the first $6 \mathrm{sec}$, all faults got the same value during the build up of rules (I). The fault $\mathrm{f}_{5}$ was injected at $10 \mathrm{sec}$ into the simulation model. Figure 11 shows that $f_{5}$ starts at approximately $13 \mathrm{sec}$. The delay between fault injection and the fuzzy model's response is $3 \mathrm{sec}$. Other faults start dropping from $10 \mathrm{sec}$ of the fuzzy model's working time (II). The BFWP at $13 \mathrm{sec}$ gets a value over 0.5. At that point, the outputs of the fuzzy model show $\mathrm{f}_{5}$ as an active fault (III). Also, other faults are not active and their graphs drop to zero. In this situation, if BFWP still occurs in the PWR model, the fault graph gets a (IV) position and others get a (V) position. In this study, at $50 \mathrm{sec}$, we suggested stopping the fault $\left(f_{5}\right)$. Figure 12 shows that the fault graph dropped suddenly to its steady-state value (VI) position and others increased to their normal state (VII) position. The steady-state value of the faults in Figure 12 could be tuned by the scaling block (see Figure 4). However, tuning drops the steady-state value below 0.5, which is the critical value of the MF that gives much better results for fault diagnosis.

Figure 12 The faults in the PWR model with $\mathrm{f}_{5}$ stopping at $50 \mathrm{sec}$

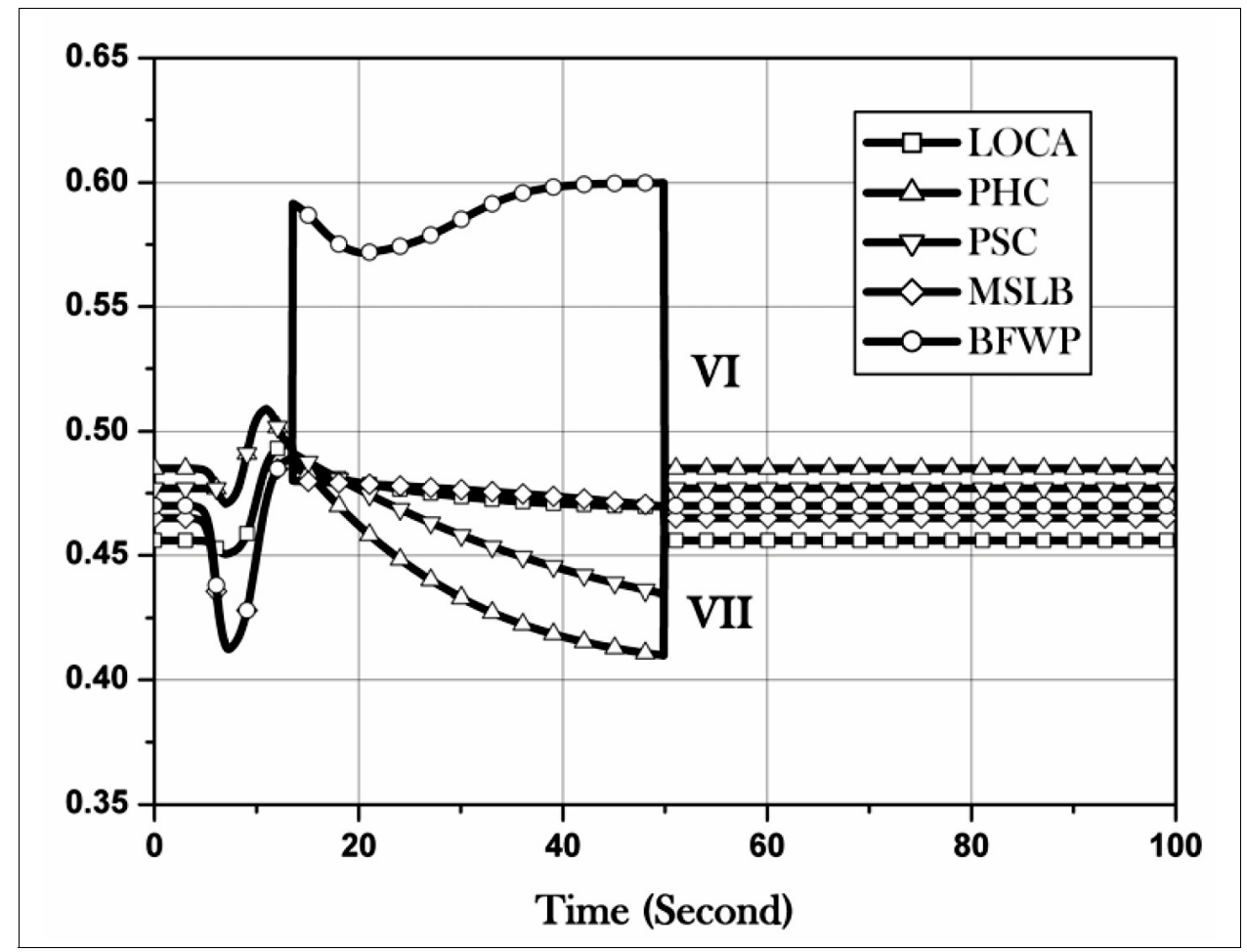

\section{Conclusion}

In this paper, fault-symptom trees were used to analyse the behaviour of the PWR with the faults. Then, the Mamdani inference strategy was used to generate fault diagnosis rules based on the operator's knowledge about fault-symptom relations. The effectiveness of fuzzy fault diagnosis has been analysed for different shapes of MFs. The performance 
of the fuzzy inference system largely depends on the selection of the MF parameters and consequent variables. From the test results, it was found that the simple and two-sided Gaussian MF is more suitable for the fuzzy fault diagnosis system. The test results of the proposed approach shows a rapid and proper response in fault diagnosis for the PWR.

\section{References}

Bartal, Y., Lin, J. and Uhrig, R.E. (1995) 'Nuclear power plant transient diagnostics using artificial neural networks that allow "don't-know" classifications', Nuclear Technology, Vol. 110, pp.436-449.

Embrechts, M.J. and Benedek, S. (2004) 'Hybrid identification of NPP transients with artificial neural networks', IEEE Transaction on Industrial Electronics, Vol. 51, No. 3, pp.686-693.

Frank, P.M. (1990) 'Fault diagnosis in dynamic systems using analytical and knowledge-based redundancy-a survey and some new results', Automatica, Vol. 26, No. 3, pp.459-474.

Isermann, R. (2005) 'Model-based fault-detection and diagnosis - status and applications', Annual Reviews in Control, Vol. 29, pp.71-85.

Marseguerra, M., Zio, E., Oldrini, A. and Brega, E. (2003) 'Fuzzy identification of transients in nuclear power plants', Nuclear Engineering and Design, Vol. 255, pp.285-294.

Naghedolfeizi, M. and Upadhyaya, B.R. (1992) 'Dynamic modeling of a pressurized water reactor power plant for diagnostics and control', 8th Power Plant Dynamics Control and Testing Symposium Proceedings, Knoxville, Tennessee, USA, Vol. 1, p.22.01.

Zio, E. and Baraldi, P. (2005) 'Identification of nuclear transients via optimized fuzzy clustering', Annals of Nuclear Energy, Vol. 32, pp.1068-1080. 